\section{Infective endocarditis complicating psittacosis: response to rifampicin}

Endocarditis rarely complicates Chlamydia psittaci infection. ${ }^{12}$ We describe a patient who developed insidious progressive aortic valve regurgitation while the psittacosis/lymphogranuloma venereum complement fixation (LGVCF) titres were rising. The infection responded to rifampicin after treatment with tetracycline had failed.

\section{Case report}

A previously healthy 43 -year-old electrician was first admitted to hospital in August 1978 with a seven-day history of generalised aches, sweating, haematuria, oliguria, vomiting, and frontal headaches. He kept pigeons but had had no contact with a parrot. There had been no ill health among his pigeons-as verified later by the public health authorities. He was feverish $\left(40^{\circ} \mathrm{C}\right)$ with sinus tachycardia of $120 / \mathrm{min}$. There were signs of left upper lobe consolidation. Cardiac auscultation was normal. Investigations: haemoglobin $14.4 \mathrm{~g} / \mathrm{dl}$; white cell count $3.4 \times 10^{9} / 1\left(3400 / \mathrm{mm}^{3}\right), 68 \%$ neutrophils, $22 \%$ lymphocytes, $10 \%$ monocytes; erythrocyte sedimentation rate $120 \mathrm{~mm}$ in $1 \mathrm{~h}$ (Westergren); arterial oxygen pressure $7.8 \mathrm{kPa}(58 \mathrm{~mm} \mathrm{Hg})$ and arterial carbon dioxide pressure $3.1 \mathrm{kPa}(23 \mathrm{~mm} \mathrm{Hg})$ on room air; urine microscopy showed numerous red cells, granular casts, and white cells; plasma sodium $123 \mathrm{mmol}(\mathrm{mEq}) / 1$, potassium $3.8 \mathrm{mmol}(\mathrm{mEq}) / 1$; blood urea $7 \mathrm{mmol} / 1(42 \mathrm{mg} / 100 \mathrm{ml})$; total serum protein $57 \mathrm{~g} / 1$, albumin $28 \mathrm{~g} / 1$; aspartate aminotransferase (AST) $174 \mathrm{IU} / 1$ (normal 5-32); gamma-glutamyltranspeptidase $49 \mathrm{IU} / 1$ (normal up to 45). Protein electrophoresis showed increase in $\alpha_{1}$ and $\alpha_{2}$ globulins. Chest $x$-ray examination confirmed left upper lobe consolidation. Tuberculin test, electrocardiogram (ECG), fluorescence antibody test against legionnaire's disease, immunoglobulins, blood cultures, and sputum examination were normal.

He was initially thought to have a "bacterial" pneumonia and was given courses of amoxycillin, flucloxacillin, benzylpenicillin, and erythromycin. $\mathrm{He}$ failed to respond significantly and remained feverish and delirious. He then developed a pulmonary embolus manifest radiologically as right lower zone collapse/consolidation of the lung. Venography showed extensive thrombus in the right femoral vein in the upper two-thirds of the thigh and the deep veins of that calf. $\mathrm{He}$ improved somewhat on anticoagulants. Fever settled and there was radiological resolution of the left upper lobe consolidation. He was discharged home. The results of virus studies were then returned, the psittacosis/LGVCF titre being 1/16. During October 1978 he had muscular aches and noticed progressive, worsening exertional dyspnoea. He was now afebrile but sinus tachycardia persisted. He had splinter haemorrhages. A summation gallop was accompanied by signs of aortic incompetence. Chest $x$-ray examination showed a small right basal effusion and resolving pneumonitis of the left upper lobe. Serial blood cultures were again negative. ECG showed first-degree heart block (P-R interval $(0.2 \mathrm{~s})$ with raised $\mathrm{S}-\mathrm{T}$ segments over the inferior leads. The psittacosis/LGVCF titre had risen to 1/32. Anticoagulation was continued. He was given oxytetracycline $4 \mathrm{~g}$ daily for six weeks. There was no clinical response and the psittacosis/LGVCF titre rose to 1/512 (December 1978). Since he had already had erythromycin he was given rifampicin $600 \mathrm{mg}$ daily for a further 16 weeks. It was then stopped. His condition improved. $\mathrm{He}$ is now well although signs of trivial aortic incompetence persist. The psittacosis/LGVCF titre fell steadily to 1/32 in May 1979.

\section{Comment}

Chlamydia are recognised as potential cardiovascular pathogens and are implicated in various acquired valvular heart diseases. ${ }^{3}$ Of the 107 cases of psittacosis dealt with by the Regional Virus Laboratory, Ruchill Hospital, Glasgow, between 1953 and 1969 five had "cardiac" features and one had endocarditis. ${ }^{4}$ Necropsy in the endocarditis case showed multivalvular lesions, pulmonary oedema, and large aortic vegetations. Our patient had no evidence of pre-existing valvular disease and developed signs of endocarditis and aortic incompetence while the psittacosis/LGVCF titres were rising. We cannot explain the rather late rise in the psittacosis/LGVCF titres. He failed to respond to large doses of tetracycline. Various other antibiotics were used without success. We are not aware of any reports of response to rifampicin, which is a bactericidal antibiotic alleged to be active at high concentration against some viruses.

The reported incidence of psittacosis is rising. In many of the patients there is no relevant "bird-contact" history. Pigeons are a major reservoir of the infecting agent. Valve damage is found in birds dying from the infection. It is rarely described in man and in the context of fatal overwhelming infections. ${ }^{1}$ We suggest that infection in relation to contact with birds be included in the differential diagnosis of "blood-culture-negative" endocarditis.
We thank Dr A D Evans, consultant virologist, University Hospital of Wales, Cardiff, and his department for help in investigating this patient.

${ }^{1}$ Levison DA, Guthrie W, Ward C, Green DM, Robertson PGC. Infective endocarditis as part of psittacosis. Lancet 1971 ;ii:844-7.

2 Ward C, Sagar HJ, Cooper D, Ward AM. Insidious endocarditis caused by Chlamydia psittaci. $B r$ Med $\mathcal{F} 1975$;iv:734-5.

${ }^{3}$ Ward C, Ward AM. Acquired valvular heart diseases in patients who keep pet birds. Lancet 1974;ii:734-6.

${ }^{4}$ Grist NR, McLean C. Infections by organisms of psittacosis/lymphogranuloma venereum group in the West of Scotland. $\mathrm{Br}$ Med $\mathrm{f}$ $1964 ;$;i : $21-5$.

(Accepted 7 November 1979)

Department of Medicine, University Hospital of Wales, Cardiff

A G. JARIWALLA, MB, MRCP, senior medical registrar

Llandough Hospital, Penarth, Cardiff

B H DAVIES, MB, MRCP, consultant physician

J WHITE, MB, MRCP, medical registrar

\section{Problems with intravenous chlormethiazole (Heminevrin) in status epilepticus}

Intravenous diazepam is a drug of first choice for status epilepticus. Administration is by either continuous intravenous infusion or bolus injection, and we have also used the rectal route successfully. For very resistant seizures, however, we have used instead a continuous intravenous infusion of chlormethiazole edisylate ${ }^{1}$ (Heminevrin) $8 \mathrm{~g} / \mathrm{l}$ in an aqueous solution of $4 \%$ dextrose, achieving control of fits in both major and minor status epilepticus with doses of $5-10 \mathrm{mg} / \mathrm{kg} / \mathrm{h}$ by titrating fits with appropriate infusion rates. Respiratory depression and hypotension have not been serious hazards. Nevertheless, we report here several problems that we have encountered with this drug.

\section{Recorded complications}

Reaction with plastics-Intravenous chlormethiazole reacts with the plastic of giving sets and may soften the burette after four to six hours' contact. No plastic paediatric giving set is completely resistant to chlormethiazole, but certain sets-for example, Avon paediatric administration sets (Avon Medicals, Birmingham, UK)-seem more resistant than others. Chlormethiazole is apparently absorbed by certain plastics, and this is being investigated by the scientific and technical branch of the Department of Health and Social Security.

Thrombophlebitis has been a serious problem, especially with infusions of over 12 hours. Long Silastic tubes produce thrombophlebitis along the whole length of contact. Chlormethiazole apparently penetrates the walls of silicone tubing, so that the response may be due to a direct action of the drug on vessel walls or a product of interaction between drug and plastic.

Fever-All five children given the drug developed slight fever (table) (not reported before to the Committee on Safety of Medicines; personal communication), and we saw three children with hyperpyrexia-namely, temperatures of $39-40^{\circ} \mathrm{C}$. There was no laboratory evidence of infection, and when chlormethiazole was stopped their temperatures fell. The manufacturers tested the solutions for pyrogens but with negative results.

Severe headache occurred in all five children: the older ones complained, but the younger ones were irritable. Sixteen other cases have been reported to the Committee on Safety of Medicines (personal communication).

Effects of Chlormethiazole on five children with seizures resistant to diazepam

\begin{tabular}{cccccc}
\hline $\begin{array}{c}\text { Case } \\
\text { No }\end{array}$ & Age & $\begin{array}{c}\text { Duration } \\
\text { in days }\end{array}$ & Headache & Thrombophlebitis & $\begin{array}{c}\text { Peak } \\
\text { temperature }\left({ }^{\circ} \mathrm{C}\right)\end{array}$ \\
\hline 1 & 3y $11 \mathrm{~m}$ & 31 & ++ & ++++ & 37.5 \\
2 & $5 \mathrm{y} 1 \mathrm{~m}$ & 4 & ++ & ++ & 38.5 \\
3 & 6y $5 \mathrm{~m}$ & 16 & +++ & ++ & 39.8 \\
4 & $8 \mathrm{y} 2 \mathrm{~m}$ & 5 & ++ & +++ & 39.6 \\
5 & $2 \mathrm{y} 8 \mathrm{~m}$ & 15 & ++ & +++ & 39.9
\end{tabular}




\section{Comment}

Continuous intravenous chlormethiazole is an effective anticonvulsant for status epilepticus, but because of the complications mentioned should be used carefully, preferably for short periods only.

We thank the scientific and technical branch of the DHSS and the Government Chemist for their interest and chemical analysis, and the manufacturers of Heminevrin (Astra Chemicals), for their analysis and pyrogen tests.

${ }^{1}$ Harvey PKP, Higenbottam TW, Loh L. Chlormethiazole in treatment of status epilepticus. $\mathrm{Br}$ Med $\mathcal{F} 1975$;ii:603-5.

(Accepted 12 November 1979)

The Hospital for Sick Children, Great Ormond Street, London WC1N 3JH

S LINGAM, DCH, MRCP, neurological registrar HELEN BERTWISTLE, RSCN, SRN, neurological ward sister HEATHER M ELLISTON, MPS, group chief pharmacist JOHN WILSON, FRCP, PHD, consultant paediatric neurologist

\section{Late displacement of central venous catheter resulting in vascular obstruction}

The introduction of large-calibre plastic catheters into the central veins of patients has facilitated total parenteral nutrition and drug administration. These two procedures may be of critical importance in managing very sick people with bacterial endocarditis, acute leukaemia during initial induction chemotherapy, or after bone marrow transplantation. In each of these the peripheral vessels are unsatisfactory routes for intravenous infusion, since large volumes need to be given and also the high viscosity or hyperosmolality of some of the materials may result in thrombophlebitis and thus render small veins especially prone to occlusion. A number of techniques are available for achieving access to the high-flow veins within the thorax. To date these procedures have been relatively free from serious problems, but the catheters may become dislocated from the original desired site and then follow an abnormal route within the thoracic vessels, leading to complications. ${ }^{1}$ In most reported cases the unsatisfactory results arise during the introduction process and we are not aware of late catheter migration, particularly against venous flow, with resulting vascular occlusion.

\section{Case report}

A 49-year-old woman was hospitalised for cytotoxic chemotherapy for stage IV lymphocytic lymphoma. In view of her poor physical state 10-gauge Silastic catheter was introduced via the left subclavian line, using a previously described technique. ${ }^{2}$ Postoperative chest $x$-ray examination confirmed that the end of the catheter was lying in the superior vena cava with its end $1 \mathrm{~cm}$ above the right atrium. For the next three weeks the patien received her intravenous drugs, hyperalimentation, and daily fluid requirements by this route without any problems. During the same period blood samples were collected from the catheter, since measurements in these correlate well with those in samples simultaneously collected from peripheral vessels. ${ }^{2}$ On day 23 after introduction of the catheter the patient's left hand and arm started to swell and this progressed slowly for two days. Careful serial examination showed increasing tenderness and swelling of the left arm, supraclavicular space, and axilla. Radiological studies showed that the radio-opaque catheter had looped up inside the superior vena cava and wedged into the axillary vein, obstructing blood flow. The catheter was simply repositioned under $x$-ray control, and within two days all symptoms had disappeared. No late complications have occurred.

\section{Comment}

A survey of central venous catheters used in our hospital over a two-year period confirmed the finding of Fischer and his colleagues that initial misplacement could occur and that intrathoracic complications may then arise. Nevertheless, once securely in position none of the catheters that we studied became displaced. Our case was the first example of late dislocation we encountered over the same two-year period, when catheters were routinely employed for hyperalimentation, induction of cytotoxic chemotherapy in patients with leukaemia, and long-term support after bone marrow transplantation. The final resting place of the catheter is all the more surprising in view of the retrograde course followed by the large diameter and relative inflexibility of the plastic tubes. This complication should be recognised as soon as it occurs since the hypertonic and irritating solutions infused may lead to local endothelial damage and thrombus formation. One way to check the patency is by regular flushing, while direct determination of venous pressure is an easy method of monitoring freedom from obstruction. While radiological control is essential when introducing the catheter its subsequent use is of lower priority in the complex management of a critically ill patient. It is therefore not surprising that the symptoms of mechanical obstruction may not be immediately evident. Since delay in diagnosis is potentially serious we suggest that these patients should be regularly examined, with particular emphasis on catheter efficiency, and that $x$-ray studies should be undertaken whenever anxiety arises. A dislocation may then be promptly corrected and $x$-ray control will thus avoid venous complications.

${ }^{1}$ Fischer J, Lundstrom J, Ottander H-G. Central venous cannulation: a radiological determination of catheter positions and immediate intrathoracic complications. Acta Anaesthesiol Scand 1977;21:45-9.

2 Jacobs P, Jacobson J. A practical method for ensuring long-term venous access. Proc $R$ Soc Med 1979;72:263-5.

(Accepted 1 November 1979)

Department of Haematology, University of Cape Town Medical School, Cape, South Africa

NICHOLAS NOVITSKY, $\mathrm{MB}$, registrar

PETER JACOBS, MD, PHD, professor and head of department

\section{Hydrallazine-induced cutaneous vasculitis}

The commonest features of the hydrallazine-associated lupus syndrome are arthralgia and malaise. Erythematous rashes may occur but vasculitis has not been reported. We have recently seen two patients with ulcerating cutaneous vasculitis associated with hydrallazine treatment.

\section{Case reports}

(1) A 63-year-old woman had been treated for hypertension and stable renal impairment for 15 years. Hydrallazine was started in September 1977 and the daily dosage increased to $250 \mathrm{mg}$ in addition to diuretic and betablocking drugs and methyldopa. In July 1978 her serum antinuclear antibody (ANA) was positive at a titre of $1 / 40$ and her erythrocyte sedimentation ratio (ESR) $33 \mathrm{~mm}$ in $1 \mathrm{~h}$. In July 1979 the ANA titre was $1 / 160$ and the ESR $70 \mathrm{~mm}$ in $1 \mathrm{~h}$. In August 1979 she was admitted to hospital with a $10 \times 5 \mathrm{~cm}$ ulcer on the lateral aspect of her left leg, which had developed over two weeks. She gave a six-month history of arthralgia, myalgia, and weight loss of $3 \mathrm{~kg}$ Two days after admission she developed multiple vasculitic lesions over the buttocks, thighs, and arms. Hydrallazine was withdrawn and the lesions began to resolve. When one of them ulcerated, however, prednisone was given for five days, with rapid disappearance of the lesions and healing of the ulcer. Results of investigations included ESR $90 \mathrm{~mm}$ in $1 \mathrm{~h}$; creatinine clearance $25 \mathrm{ml} / \mathrm{min}$; no proteinuria; haemoglobin $11.4 \mathrm{~g} / \mathrm{dl}$; white cell count (WBC) $4.1 \times 10^{9} / 1\left(4100 / \mathrm{mm}^{3}\right)$, normal differential and platelets immunoglobulins IgG $13.0 \mathrm{~g} / \mathrm{l}, \mathrm{IgA} 1.75 \mathrm{~g} / \mathrm{l}, \mathrm{IgM} 2.60 \mathrm{~g} / 1$ (normal IgM $0.5-1.8 \mathrm{~g} / \mathrm{l})$. IgG and IgM ANA titres were $1 / 2560$, DNA binding $20 \%$. No other autoantibodies were found, complement screen was normal, Clq binding negative, and cryoglobulins were present in trace only. Sulphamethazine phenotyping showed her to be a slow acetylator and her total intake of hydrallazine was estimated to be $120 \mathrm{~g}$. Histology of a lesion from her thigh showed allergic vasculitis with fibrinoid necrosis of small vessels. Immunofluorescence microscopy showed deposits of IgM, fibrin, and C3 in small blood vessels.

(2) A 61-year-old woman with essential hypertension had received hydrallazine, propranolol, and cyclopenthiazide $\mathrm{K}$ for two years. During this time her maximum daily dosage of hydrallazine was $100 \mathrm{mg}$ and her estimated total intake $95 \mathrm{~g}$. In 1979 she presented with a six-month history of pain and stiffness in her hands, wrists, elbows, shoulders, and knees 